\title{
Potential of Methyl Jasmonate as a Harvest Aid for 'Thompson Seedless' Grapes: Concentration and Time Needed for Consistent Berry Loosening
}

\author{
Raquel González-Herranz \\ Universidad de Valladolid, Departamento de Producción Vegetal, \\ E.T.S.I.I.A.A., Avnd. Madrid, 57, C.P. 34004, Palencia, Spain
}

Kimberley A. Cathline and Matthew W. Fidelibus ${ }^{1}$ University of California, Department of Viticulture and Enology, One Shields Avenue, Davis, CA 95616-5270

\author{
Jacqueline K. Burns \\ University of Florida, Citrus Research and Education Center, Institute of \\ Food and Agricultural Sciences, 700 Experiment Station Road, Lake Alfred, \\ FL 33850-2299
}

Additional index words. abscission agents, grape (Vitis vinifera L.), mechanization, plant growth regulators, raisins

\begin{abstract}
The application of methyl jasmonate (MeJA) to grapes (Vitis vinifera L.) may decrease fruit detachment force (FDF) and promote the development of dry stem scars on the berries, both of which could improve the quality of machine-harvested raisin grapes. However, treatment with MeJA also promotes preharvest fruit drop, which is undesirable. Thus, experiments were conducted to determine how the concentration of MeJA applied and time after treatment affect FDF and abscission of grapes. Mature 'Thompson Seedless' grapevines were treated with one of five different solutions containing 0, 0.2, 2, 10, or $20 \mathrm{~mm}$ MeJA, and FDF and fruit abscission were monitored for $\approx 2$ weeks. Treatment with 2 mM or less MeJA had inconsistent effects on FDF and did not promote abscission, whereas treatment with 10 to 20 mM MeJA reduced FDF within 2 to 3 days after treatment (DAT) and promoted abscission, which began on $\approx 3$ DAT and persisted for $\approx 8 \mathrm{DAT}$. Thus, to optimize the use of MeJA as a harvest aid for 'Thompson Seedless' may require application of between 2 and $10 \mathrm{~mm}$ MeJA followed by harvest within 3 DAT.
\end{abstract}

Raisin-making has traditionally been a labor-intensive activity, but California growers are increasingly adopting mechanized production methods to reduce cost and thereby help ensure economic sustainability (Christensen, 2000; Sánchez et al., 2008). One mechanized production method is dryon-vine (DOV). In the DOV method, canes bearing mature fruits are severed, causing them to dry into raisins on the trellised vines, from which they are mechanically harvested (Fidelibus et al., 2008). This method has seen limited adoption because traditional 'Thompson Seedless' raisin vineyards are poorly suited for DOV (Fidelibus et al., 2007b), and the establishment of new DOV vineyards requires a substantial capital investment (Sánchez et al., 2008).

Received for publication 11 Mar. 2009. Accepted for publication 4 May 2009.

This work was made possible by a grant from the California Raisin Marketing Board.

We are grateful to Jorge Osorio Aguilar and Socorro Cisneros for technical assistance.

${ }^{1}$ To whom reprint requests should be addressed; e-mailmwf@uckac.edu.
Instead, most raisin grapes are currently shaken from the vines with a mechanical harvester and then deposited onto a long sheet of paper called a "continuous tray" to dry (Christensen, 2000; Sánchez et al., 2008). Later, another machine is used to pick up the dried raisins from the tray. The main problem with this method is that the harvest machines, which were designed for juice and wine grapes, can impart excessive mechanical damage to the grapes, rendering them unsuitable for raisin-making (Fidelibus et al., 2007a). Some of the mechanical damage is the result of tearing of the stem end, which occurs when the berries are detached from their pedicels (Studer and Olmo, 1974). This type of damage is minimized by severing the fruit-bearing canes $\approx 1$ week before harvest, which reduces fruit detachment force (FDF) and causes the rachis to become dry and brittle so that the cluster tends to break apart during harvest, allowing some berries to remain attached to their pedicels (Fidelibus et al., 2007a; Studer and Olmo, 1971, 1974).

When executed well, cane severance reduces mechanical damage, but in practice, results are variable because environmental conditions affect the physical characteristics of the rachises (Studer, 2000), and pruning crews often miss some canes. If there is a high proportion of grapes on missed canes or on basal shoots, which are not severed, they must be removed before harvest to prevent them from reducing the overall quality of the crop (Studer and Olmo, 1974). Furthermore, the need for cane severance, which cannot be mechanized in most traditional vineyards, detracts from the industry's goal of complete harvest mechanization. Recently, we discovered that the application of methyl jasmonate (MeJA) to grapes can reduce FDF to a similar extent as cane severance and thus might offer an alternative to cane severance (Fidelibus et al., 2007a). The purpose of this study was to verify the concentration of MeJA needed for consistent loosening and to determine how the time between application and harvest may affect FDF and preharvest fruit abscission.

\section{Materials and Methods}

The experiments were conducted in a 'Thompson Seedless' raisin vineyard at the Kearney Agricultural Center, Parlier, CA. The vines, which were planted in the mid1960 s, were head-trained and cane-pruned. The vineyard was divided into 20 plots, each consisting of four vines in a row. Nontreated vines surrounded each plot within and between rows. The plots were assigned to receive solutions containing $0,0.2,2,10$, or $20 \mathrm{~mm}$ MeJA (Bedoukian Research Inc., Danbury, CT) with $0.2 \%$ Latron-B 1956 spreader-sticker (Loveland Industries Inc., Greeley, CO), replicated four times, in a randomized complete block design. Vines were treated on 20 Sept. 2007 and 15 Sept. 2008, when grapes had amassed sufficient soluble solids (19 to $20^{\circ} \mathrm{Brix}$ ) for raisinmaking. Immediately before applying the solutions, three clusters of grapes were randomly collected from each plot, and five rachis sections from the top, middle, and bottom portions of each cluster were prepared by cutting the rachises with shears. A berry from each rachis section was placed in a jig attached to a force gauge (DPS-11; Imada, Northbrook, IL) and force parallel to the fruit axis was applied to the rachis until it detached from the berry, at which time peak force was recorded.

A motorized backpack sprayer (Solo, Newport News, RI) was used to apply the MeJA solutions to fruit and foliage in the fruiting zone until runoff. The next day, three randomly selected clusters in each plot were loosely enclosed in plastic mesh citrus bags to catch any berries that might abscise. Each bag was modified by creating a resealable flap at the bottom of the bags, which enabled us to remove any abscised berries from the bags without causing excessive disturbance to the clusters. In 2007, the bags were inspected on 4, 7, 10, 14, and $17 \mathrm{~d}$ after treatment (DAT), at which time any berries that abscised were counted. Additional berries were randomly collected from other 
clusters in the plot, homogenized in a blender, and soluble solids of the filtered juice were measured with a temperaturecompensating digital refractometer (Palette 101; Atago, Farmingdale, NY). In 2008, similar data, with the exception of soluble solids, were collected on 2, 3, 4, 5, 8, and 16 DAT.

In 2007, three nonbagged clusters were randomly selected and harvested from each plot on each of the same days that preharvest berry abscission was noted. In 2008, clusters were collected on $0,2,4,8$, and 16 DAT. Berries from the harvested clusters were then subjected to FDF measurements as described previously. On the final observation date in each year, the proportion of abscised berries on each date was determined by dividing the total number of loose berries collected from the bags by the sum of the number of abscised berries and those still attached to the clusters. In 2008, the stem end of berries detached in the course of making FDF measurements was evaluated on 16 DAT, and the proportion of berries with pedicels still attached, a dry stem scar (well-developed abscission layer), or a wet stem scar (poorly developed or no abscission layer) was noted.

All data were subjected to analysis of variance using SAS statistical software (SAS Inst., Cary, NC). The concentration of MeJA applied strongly interacted with DAT to affect FDF and fruit drop, so data were summarized in two-way tables to show the effects of MeJA treatment on each DAT and the effect of DAT on each MeJA treatment
(Gomez and Gomez, 1984). Response variables were also evaluated with linear, quadratic, and cubic contrasts based on the MeJA or DAT treatments.

\section{Results}

In 2007, FDF decreased throughout the course of the study, whether or not the vines were treated with MeJA (Table 1). Even so, the FDF of vines treated with $10 \mathrm{~mm}$ or greater MeJA was at least $25 \%$ less than the FDF of vines subjected to some other treatments on several dates between 3 and 17 DAT. In 2008, FDF from nontreated vines were considerably lower than those observed in 2007 and they remained about the same throughout the study period, whereas FDF from vines treated with 0.2 to $10 \mathrm{~mm}$ MeJA declined between 2 and 8 DAT and then returned to pretreatment values by $16 \mathrm{DAT}$ (Table 2). The FDF from vines treated with $20 \mathrm{~mm}$ MeJA also declined by 2 DAT, but they remained low throughout the study period (Table 2). On 4 DAT, $\approx 25 \%$ less force was needed to detach fruit from vines treated with 0.2 or $2 \mathrm{~mm}$ MeJA compared with untreated vines, but the effects of those relatively low doses of MeJA were not persistent. In contrast, application of $10 \mathrm{~mm}$ or greater MeJA reduced FDF by half within $2 \mathrm{DAT}$, and effects persisted for 8 to $16 \mathrm{DAT}$.

Treatment with $10 \mathrm{~mm}$ or greater MeJA promoted the development of dry stem scars and reduction of wet stem scars on berries detached during the course of FDF measurements; treated berries were three times as likely to have dry stem scars as nontreated berries (Table 3 ). In 2007, the 1 year that possible treatment effects on soluble solids were evaluated, berries from all treatments had similar soluble solids on five of the six measurement days (data not shown).

In both years, a significant proportion of berries on vines treated with $10 \mathrm{~mm}$ or greater MeJA abscised within 3 DAT (Tables 4 and 5). More than $60 \%$ of the berries that abscised in 2007 were shed within 7 DAT, and most of the others that abscised did so by 10 DAT (Table 4). Based on the results from 2007, inspection dates in 2008 were concentrated within the first week of treatment when, again, most abscission took place (Table 5). In fact, treatment effects were evident within 2 DAT, and most of the berries that abscised did so within 3 to $4 \mathrm{DAT}$.

\section{Discussion}

A preliminary study showed that treatment with 0.2 or 2 mM MeJA can reduce FDF (Fidelibus et al., 2007a), but the data reported here suggest that these relatively low concentrations of MeJA may have inconsistent effects. Treatment with 10 to $20 \mathrm{~mm}$ MeJA induced rapid, consistent, and longer-lasting reductions in FDF as observed on Citrus sinensis (Hartmond et al., 2000). The reason why the FDF from vines treated with 2 or 10 mM MeJA increased between 8 and 16 DAT

Table 1. Effect of methyl jasmonate (MeJA) treatment and days after treatment on fruit detachment force (FDF) of 'Thompson Seedless' grapes, Parlier, CA, 2007.

\begin{tabular}{|c|c|c|c|c|c|c|c|c|}
\hline \multirow[b]{3}{*}{ MeJA (mm) } & \multicolumn{6}{|c|}{ FDF (kg) } & \multirow[b]{3}{*}{$\operatorname{Pr}>\mathrm{F}$} & \multirow[b]{3}{*}{ Contrasts $^{y}$} \\
\hline & \multicolumn{6}{|c|}{ Days after treatment } & & \\
\hline & 0 & 3 & 7 & 10 & 14 & 17 & & \\
\hline 0 & $0.190^{z} A$ & $0.134 \mathrm{~b} \mathrm{~B}$ & $0.114 \mathrm{~B}$ & $0.141 \mathrm{a} B$ & $0.125 \mathrm{~B}$ & $0.114 \mathrm{ab} \mathrm{B}$ & $<0.01$ & $\mathrm{~L}^{* *}, \mathrm{Q}^{* *}, \mathrm{C}^{*}$ \\
\hline 0.2 & $0.174 \mathrm{~A}$ & 0.170 a $\mathrm{A}$ & $0.133 \mathrm{~B}$ & 0.153 a $\mathrm{AB}$ & $0.118 \mathrm{~B}$ & $0.141 \mathrm{a} A B$ & 0.02 & $\mathrm{~L}^{*}, \mathrm{Q} \mathrm{NS}, \mathrm{C}$ NS \\
\hline 2 & $0.190 \mathrm{~A}$ & 0.180 a $\mathrm{A}$ & $0.131 \mathrm{~B}$ & 0.164 a $\mathrm{AB}$ & $0.137 \mathrm{~B}$ & $0.130 \mathrm{ab} B$ & $<0.01$ & $\mathrm{~L}^{* *}, \mathrm{Q} \mathrm{NS}, \mathrm{C}$ NS \\
\hline 10 & $0.184 \mathrm{~A}$ & $0.102 \mathrm{~b} \mathrm{~B}$ & $0.077 \mathrm{~B}$ & 0.096 b B & $0.094 \mathrm{~B}$ & 0.095 b B & $<0.01$ & $\mathrm{~L}^{* *}, \mathrm{Q}^{* *}, \mathrm{C} \mathrm{NS}$ \\
\hline 20 & $0.165 \mathrm{~A}$ & $0.091 \mathrm{~b} \mathrm{~B}$ & $0.110 \mathrm{~B}$ & $0.094 \mathrm{~b} \mathrm{~B}$ & $0.085 \mathrm{~B}$ & $0.098 \mathrm{~b} \mathrm{~B}$ & 0.04 & $\mathrm{~L}^{* *}, \mathrm{Q} \mathrm{NS}, \mathrm{C}$ NS \\
\hline $\operatorname{Pr}>\mathrm{F}$ & 0.49 & $<0.01$ & 0.15 & 0.01 & 0.12 & 0.05 & & \\
\hline Contrasts & L NS, Q NS, C NS & $\mathrm{L}^{*}, \mathrm{Q}^{*}, \mathrm{C}$ NS & L NS, Q NS, C NS & $\mathrm{L}^{* *}, \mathrm{Q}$ NS, C NS & $\mathrm{L}^{*}, \mathrm{Q}$ NS, $\mathrm{C}$ NS & $\mathrm{L}^{*}, \mathrm{Q}$ NS, $\mathrm{C}^{*}$ & & \\
\hline
\end{tabular}

${ }^{2}$ Values are treatment means, $\mathrm{n}=4$. Within columns, means are significantly different if followed by a different lower case letter according to Duncan's new multiple range test (DNMRT). Within rows, means are significantly different if followed by a different upper case letter according to DNMRT.

${ }^{y}$ Significance of linear $(\mathrm{L})$, quadratic $(\mathrm{Q})$, or cubic $(\mathrm{C})$ trends for fruit detachment force in response to days after treatment (within rows) or MeJA treatments (within columns); significant at the $5 \%(*), 1 \%(* *)$, or $0.1 \%(* * *)$ level, or nonsignificant (Ns).

Table 2. Effect of methyl jasmonate (MeJA) treatment and days after treatment on fruit detachment force (FDF) of 'Thompson Seedless' grapes, Parlier, CA, 2008.

\begin{tabular}{|c|c|c|c|c|c|c|c|}
\hline \multirow[b]{3}{*}{ MeJA (mM) } & \multicolumn{5}{|c|}{ FDF $(\mathrm{kg})$} & \multirow[b]{3}{*}{$\operatorname{Pr}>\mathrm{F}$} & \multirow[b]{3}{*}{ Contrasts $^{\mathrm{y}}$} \\
\hline & \multicolumn{5}{|c|}{ Days after treatment (DAT) } & & \\
\hline & 0 & 2 & 4 & 8 & 16 & & \\
\hline 0 & $0.069^{\mathrm{z}}$ & $0.047 \mathrm{a}$ & $0.075 \mathrm{a}$ & $0.061 \mathrm{a}$ & $0.076 \mathrm{a}$ & 0.10 & L NS, Q NS, C NS \\
\hline 0.2 & $0.068 \mathrm{AB}$ & $0.051 \mathrm{a} \mathrm{B}$ & $0.057 \mathrm{~b} \mathrm{~B}$ & $0.051 \mathrm{a} \mathrm{B}$ & 0.089 a A & 0.04 & $\mathrm{~L}$ NS, $\mathrm{Q}^{* *}, \mathrm{C}_{\mathrm{NS}}$ \\
\hline 2 & $0.063 \mathrm{AB}$ & 0.042 a B & $0.054 \mathrm{~b} \mathrm{AB}$ & $0.055 \mathrm{a} A B$ & 0.076 a A & 0.03 & $\mathrm{~L}_{\mathrm{NS}}, \mathrm{Q}^{*}, \mathrm{C}_{\mathrm{NS}}$ \\
\hline 10 & $0.072 \mathrm{~A}$ & $0.026 \mathrm{~b} \mathrm{C}$ & 0.035 с C & $0.037 \mathrm{~b} \mathrm{BC}$ & $0.056 \mathrm{ab} \mathrm{AB}$ & $<0.01$ & $\mathrm{~L}$ NS, $\mathrm{Q}^{* * *}, \mathrm{C}$ NS \\
\hline 20 & $0.078 \mathrm{~A}$ & $0.026 \mathrm{~b} \mathrm{~B}$ & 0.032 c B & 0.028 b B & $0.033 \mathrm{~b} \mathrm{~B}$ & $<0.01$ & $\mathrm{~L}^{* *}, \mathrm{Q}^{* *}, \mathrm{C}^{*}$ \\
\hline $\operatorname{Pr}>\mathrm{F}$ & 0.88 & $<0.01$ & $<0.01$ & $<0.01$ & 0.02 & & \\
\hline Contrasts & L NS, Q Ns, C NS & $\mathrm{L}^{* *}, \mathrm{Q} \mathrm{NS}, \mathrm{C}$ NS & $\mathrm{L}^{* * *}, \mathrm{Q} \mathrm{NS}, \mathrm{C}^{*}$ & $\mathrm{~L}^{* * *}, \mathrm{Q} \mathrm{NS}, \mathrm{C}^{* *}$ & $\mathrm{~L}^{*}, \mathrm{Q}$ NS, C NS & & \\
\hline
\end{tabular}

${ }^{z}$ Values are treatment means, $\mathrm{n}=4$. Within columns, means are significantly different if followed by a different lower case letter, according to Duncan's new multiple range test (DNMRT). Within rows, means are significantly different if followed by a different upper case letter according to DNMRT.

${ }^{y}$ Significance of linear (L), quadratic (Q), or cubic (C) trends for fruit detachment force in response to DAT (within rows) or MeJA treatment (within columns); significant at the $5 \%(*), 1 \%(* *)$, or $0.1 \%(* * *)$ level, or nonsignificant (NS). 
in 2008 is uncertain, and several possible explanations should be considered in future research.

First, nonreacting berries may have been incompletely covered with MeJA solutions. A second possibility is that MeJA has transient effects on some berries. Support for this hypothesis comes from Hartmond et al. (2000) who reported that FDF of 'Valencia' oranges (Citrus sinensis) treated with MeJA declined between 7 and 14 DAT and then returned to pretreatment levels thereafter. Such a response could indicate that some berries may have loosened but not abscised, and the partially digested abscission zones could have undergone a process of wound healing that increased FDF measurements. Another likely possibility is that most of the berries remaining by 16 DAT were in one of two classes: either very loosely attached and therefore detached before FDF measurements could be made or they did not respond to MeJA at all and thus had the same FDF as they did before treatment. We observed that the process of picking and handling the clusters and preparing the samples for FDF measurements invariably detached the loosest berries, but did not quantify this response.

Fruit drop was concurrent with, or followed effects on, FDF. Thus, vines treated with $10 \mathrm{~mm}$ or greater MeJA should probably be harvested within 2 or 3 DAT to avoid excessive preharvest fruit drop and to capitalize on the significant population of fruit that had loosened by then. Here again, there are parallels with Citrus sinensis, from which

Table 3. Effect of methyl jasmonate (MeJA) treatment on the stem end condition of 'Thompson Seedless' berries detached from cluster sections during the course of fruit detachment force measurements made $16 \mathrm{~d}$ after treatment, Parlier, CA, 2008.

\begin{tabular}{lccc}
\hline & \multicolumn{3}{c}{ Stem end condition } \\
\cline { 2 - 4 } MeJA (mM) & Pedicel attached to berry (\%) & Dry scar (\%) & Wet scar (\%) \\
\hline 0 & $18^{\mathrm{z}}$ & $15 \mathrm{~b}$ & $67 \mathrm{a}$ \\
0.2 & 12 & $10 \mathrm{~b}$ & $78 \mathrm{a}$ \\
2 & 10 & $17 \mathrm{~b}$ & $73 \mathrm{a}$ \\
10 & 5 & $52 \mathrm{a}$ & $43 \mathrm{~b}$ \\
20 & 5 & $60 \mathrm{a}$ & $35 \mathrm{~b}$ \\
Pr $>$ F & 0.30 & $<0.01$ & $<0.01$ \\
Contrasts $^{y}$ & $\mathrm{~L}^{*}, \mathrm{Q}$ NS, C NS & $\mathrm{L}^{* * *}, \mathrm{Q}^{*}, \mathrm{C}$ NS & $\mathrm{L}^{* * *}, \mathrm{Q}^{*}, \mathrm{C} \mathrm{NS}$ \\
\hline
\end{tabular}

${ }^{2}$ Values are treatment means, $\mathrm{n}=4$. Within columns, means are significantly different if followed by a different letter, according to Duncan's new multiple range test.

${ }^{\mathrm{y}}$ Significance of linear (L), quadratic (Q), or cubic (C) trends for stem end condition in response to MeJA treatments (within columns); significant at the $5 \%(*), 1 \%(* *)$, or $0.1 \%(* * *)$ level, or nonsignificant (NS).

the most rapid rate of fruit drop occurred within the first week of treatment (Hartmond et al., 2000). Effects on total cumulative fruit drop generally agreed with our previous observation that treatment with $2 \mathrm{~mm}$ or less MeJA did not promote fruit drop, but treatment with $10 \mathrm{~mm}$ or greater MeJA induced $25 \%$ to $50 \%$ fruit drop by 10 DAT (Fidelibus et al., 2007a).

Berry detachment usually damages the stem end of Vitis vinifera berries (Kou et al., 2007), resulting in a wet stem scar. Wet stem scars provide an entry point for pathogenic microorganisms (Ballinger and Nesbitt, 1982; Kou et al., 2007) and therefore encourage decay. They also enable juice to leak from the berries, which makes them sticky so that sand and other debris adhere to the berries, becoming embedded in the raisins as they dry (Studer, 2000). Therefore, the promotion of dry stem scars by treatment with $10 \mathrm{~mm}$ or greater MeJA is a highly desirable response.

In conclusion, the FDF and fruit drop data suggest that treatment effects occur within a few days, and between 2 and 10 mM MeJA is needed to induce significant, sustained loosening. The data also suggest that most of the treatment effects are completed within 8 DAT as evidenced by the slight increase in FDF between 8 and 16 DAT, and the few additional berries that abscised during that time. Thus, vines treated with MeJA should probably be harvested within 3 DAT. Cane severance, the current industry standard for loosening fruit, is usually performed at least

Table 4. Effect of methyl jasmonate (MeJA) treatment and days after treatment on cumulative berry abscission of 'Thompson Seedless' grapes, Parlier, CA, 2007.

\begin{tabular}{|c|c|c|c|c|c|c|c|}
\hline \multirow[b]{3}{*}{$\mathrm{MeJA}(\mathrm{mm})$} & \multicolumn{5}{|c|}{ Cumulative abscised berries (\%) } & \multirow[b]{3}{*}{$\mathrm{P}>\mathrm{F}$} & \multirow[b]{3}{*}{ Contrasts $^{\mathrm{y}}$} \\
\hline & \multicolumn{5}{|c|}{ Days after treatment } & & \\
\hline & 3 & 7 & 10 & 14 & 17 & & \\
\hline 0 & $0.00 \mathrm{c}^{\mathrm{z}}$ & $0.04 \mathrm{~b}$ & $0.25 \mathrm{~b}$ & $1.76 \mathrm{~b}$ & $1.80 \mathrm{~b}$ & 0.15 & $\mathrm{~L}^{*}, \mathrm{Q} \mathrm{NS}, \mathrm{C}$ NS \\
\hline 0.2 & $0.32 \mathrm{c}$ & $0.32 \mathrm{~b}$ & $0.38 \mathrm{~b}$ & $0.41 \mathrm{~b}$ & $0.41 \mathrm{~b}$ & 0.98 & L NS, Q NS, C NS \\
\hline 2 & $0.00 \mathrm{c}$ & $0.37 \mathrm{~b}$ & $0.40 \mathrm{~b}$ & $0.49 \mathrm{~b}$ & $0.54 \mathrm{~b}$ & 0.12 & $\mathrm{~L}^{*}, \mathrm{Q} \mathrm{NS}, \mathrm{C} \mathrm{NS}$ \\
\hline 10 & $4.95 \mathrm{~b} \mathrm{C}$ & 25.05 a B & $35.21 \mathrm{a} \mathrm{AB}$ & 40.83 a $\mathrm{A}$ & $43.23 \mathrm{a} \mathrm{A}$ & $<0.01$ & $\mathrm{~L}^{* * *}, \mathrm{Q}^{*}, \mathrm{C} \mathrm{NS}$ \\
\hline 20 & 10.31 a C & 24.19 a B & $31.51 \mathrm{a} \mathrm{AB}$ & 35.76 a $\mathrm{AB}$ & 37.05 a A & $<0.01$ & $\mathrm{~L}^{* * *}, \mathrm{Q}$ NS, $\mathrm{C}$ NS \\
\hline $\operatorname{Pr}>\mathrm{F}$ & $<0.01$ & $<0.01$ & $<0.01$ & $<0.01$ & $<0.01$ & & \\
\hline Contrasts & $\mathrm{L}^{* * *}, \mathrm{Q}^{*}, \mathrm{C}$ NS & $\mathrm{L}^{* * *}, \mathrm{Q}$ NS, $\mathrm{C}^{*}$ & $\mathrm{~L}^{* * *}, \mathrm{Q}^{*}, \mathrm{C}^{* * *}$ & $\mathrm{~L}^{* * *}, \mathrm{Q}^{*}, \mathrm{C}^{* * *}$ & $\mathrm{~L}^{* * *}, \mathrm{Q}^{*}, \mathrm{C}^{* * *}$ & & \\
\hline
\end{tabular}

${ }^{\mathrm{z}}$ Values are treatment means, $\mathrm{n}=4$. Within columns, means are significantly different if followed by a different lower case letter, according to Duncan's new multiple range test (DNMRT). Within rows, means are significantly different if followed by a different upper case letter according to DNMRT.

${ }^{y}$ Significance of linear (L), quadratic (Q), or cubic (C) trends for berry abscission in response to DAT (within rows) or MeJA treatments (within columns); significant at the $5 \%(*), 1 \%(* *)$, or $0.1 \%(* * *)$ level, or nonsignificant (NS).

Table 5. Effect of methyl jasmonate (MeJA) treatment and days after treatment on cumulative berry abscission of 'Thompson Seedless' grapes, Parlier, CA, 2008.

\begin{tabular}{|c|c|c|c|c|c|c|c|c|c|}
\hline \multirow[b]{3}{*}{ MeJA (mм) } & \multicolumn{7}{|c|}{ Cumulative abscised berries (\%) } & \multirow[b]{3}{*}{$\operatorname{Pr}>F$} & \multirow[b]{3}{*}{ Contrasts $^{y}$} \\
\hline & \multicolumn{7}{|c|}{ Days after treatment } & & \\
\hline & 0 & 2 & 3 & 4 & 5 & 8 & 16 & & \\
\hline 0 & $0^{z}$ & 0.5 & $0.5 \mathrm{c}$ & $0.5 \mathrm{c}$ & $0.5 \mathrm{c}$ & $0.5 \mathrm{c}$ & $0.5 \mathrm{c}$ & 0.66 & L Ns, Q NS, C NS \\
\hline 2 & $0 \mathrm{C}$ & $0.2 \mathrm{BC}$ & $0.3 \mathrm{c} \mathrm{ABC}$ & $0.3 \mathrm{c} \mathrm{ABC}$ & $0.6 \mathrm{c} \mathrm{AB}$ & $0.7 \mathrm{c} \mathrm{A}$ & $0.8 \mathrm{c} \mathrm{A}$ & 0.03 & $\mathrm{~L}^{* *}, \mathrm{Q} \mathrm{NS}, \mathrm{C}$ NS \\
\hline 10 & $0 \mathrm{~B}$ & $1.2 \mathrm{~B}$ & $16.1 \mathrm{~b} \mathrm{~A}$ & $20.0 \mathrm{~b} \mathrm{~A}$ & 24.4 b A & $28.1 \mathrm{~b} \mathrm{~A}$ & $29.4 \mathrm{~b} \mathrm{~A}$ & $<0.01$ & $\mathrm{~L}^{* * *}, \mathrm{Q}$ NS, C NS \\
\hline 20 & $0 \mathrm{C}$ & $4.4 \mathrm{C}$ & 26.5 a B & 35.8 a $\mathrm{AB}$ & 42.3 a A & 48.7 a A & 49.9 a A & $<0.01$ & $\mathrm{~L}^{* * *}, \mathrm{Q}$ NS, C NS \\
\hline $\operatorname{Pr}>F$ & 0.42 & 0.09 & $<0.01$ & $<0.01$ & $<0.01$ & $<0.01$ & $<0.01$ & & \\
\hline
\end{tabular}

${ }^{2}$ Values are treatment means, $n=4$. Within columns, means are significantly different if followed by a different lower case letter, according to Duncan's new multiple range test (DNMRT). Within rows, means are significantly different if followed by a different upper case letter, according to DNMRT.

${ }^{y}$ Significance of linear (L), quadratic $(\mathrm{Q})$, or cubic $(\mathrm{C})$ trends for berry abscission in response to DAT (within rows) or MeJA treatments (within columns); significant at the $5 \%(*), 1 \%(* *)$, or $0.1 \%(* * *)$ level, or nonsignificant (NS). 
$7 \mathrm{~d}$ before harvest (Christensen, 2000), so in future tests, to compare the efficacy of cane severance with MeJA, cane severance should probably be conducted $\approx 3$ or $4 \mathrm{~d}$ before MeJA is applied.

\section{Literature Cited}

Ballinger, W.E. and W.B. Nesbitt. 1982. Postharvest decay of muscadine grapes (Carlos) in relation to storage temperature, time, and stem condition. Amer. J. Enol. Viticult. 33:173-175.

Christensen, L.P. 2000. Current developments in harvest mechanization and DOV, p. 252-263. In: Christensen, L.P. (ed.). Raisin production manual. University of California, Agricultural and Natural Resources, Oakland, CA.

Fidelibus, M.W., K.A. Cathline, and J.K. Burns. 2007a. Potential abscission agents for raisin, table, and wine grapes. HortScience 42:16261630.

Fidelibus, M.W., S.J. Vasquez, and K.A. Cathline. 2007b. Canopy separation and defoliation do not improve the dry-on-vine raisin-making method for 'Thompson Seedless' grapevines on traditional trellises. J. Amer. Pomol. Soc. 61:61-70.

Fidelibus, M.W., L.P. Christensen, D.G Katayama, and D.W. Ramming. 2008. Earlyripening grapevine cultivars for dry-on-vine raisins on an open-gable trellis. HortTechnology $18: 740-745$.

Gomez, K.A. and A.A. Gomez. 1984. Statistical procedures for agricultural research. Wiley Interscience, New York, NY.

Hartmond, U., R. Yuan, J.K. Burns, A. Grant, and W.J. Kender. 2000. Citrus fruit abscission induced by methyl-jasmonate. J. Amer. Soc. Hort. Sci. 125:547-552.
Kou, L., Y. Luo, D. Wu, and X. Liu. 2007. Effects of mild heat treatment on microbial growth and product quality of packaged fresh-cut table grapes. J. Food Sci. 72:567-573.

Sánchez, D.S., M.A. Boland, and D. Sumner. 2008. Sun-Maid growers of California. Rev. Agr. Econ. 30:360-369.

Studer, H.E. 2000. Raisin harvest mechanization: A bit of history, p. 245-251. In: Christensen, L.P. (ed.). Raisin production manual. University of California, Agricultural and Natural Resources, Oakland, CA.

Studer, H.E. and H.P. Olmo. 1971. The severed cane technique and its application to mechanical harvesting of raisin grapes. Trans. ASAE 14:38-43.

Studer, H.E. and H.P. Olmo. 1974. Parameters affecting the quality of machine harvested raisins. Trans. ASAE 17:783-786. 